\title{
EFFECT OF MATERIAL PROPERTIES ON VIBRATIONS OF NONSYMMETRICAL AXIALLY LOADED THIN-WALLED EULER-BERNOULLI BEAMS
}

\author{
Gökhan Altıntaş \\ Department of Mechanical Engineering \\ Celal Bayar University, 45140 \\ Muradiye, Manisa, Turkey \\ gokhanaltintas@mekanik.net
}

\begin{abstract}
This paper focuses on effect of material properties on free vibration characteristics of nonsymmetrical axially loaded thin-walled Euler-Bernoulli beams. Many scientists studied the vibration of coupled systems but adequate consideration has not been given to detailed and parametric studies on the effect of material properties on vibration properties. The current findings of this study show that there have been quite different effects of material properties on the systems without symmetry axis than on the systems with symmetry axis. Material properties are properties affecting the free vibration behavior. Moreover, effect of axial load on natural frequencies was also investigated in this study. Convergence work revealed that the current mathematical model simulated the problem with excellent accuracy.
\end{abstract}

Key Words- Effect of Material Properties, Triply Coupled Systems, Coupled Modes, Mode Order Change

\section{INTRODUCTION}

A number of studies dealing with coupled vibrations of thin-walled beams have been developed. Gere and Lin [1] and Lin [2] provided some of the first analytical works in this field and obtained the coupled, natural vibration behaviors of uniform, open-section channels using the Rayleigh Ritz method. The various beam theories for the solution of beams having coupled torsion and bending were compared by Bishop et al. [3]. Freiberg presented a numerical method for the solution of coupled beam vibrations based on Vlasov theory and derived the dynamic stiffness matrix [4]. He developed element mass and stiffness matrices for use in standard finite element techniques and evaluated the modal masses. Dokumaci [5] derived the exact analytical expression for the solution of torsional bending equations and the results of this study were later extended by Bishop et al. [6] to include warping, especially significant for thin-walled section beams. The use of this method was found to be extremely convenient and effective when the responses of finite, uniform structures to point harmonic forces or line harmonic loads were determined [7]. Banerjee and Williams [8] took into account the effect of axial load. Yaman [9] investigated the triply coupled vibrations of open-section channels by wave analysis method and the coupled wave numbers, various frequency response curves and the mode shapes were presented for undamped and structurally damped channels. Yaman [10] also developed exact analytical models for the analysis of non-classical end boundary conditions in purely 
torsional and doubly coupled vibrations of single-bay channels. The exact methods have alleviated the difficulties encountered in the consideration of complex end boundary conditions and were proved to be effective. Tanaka and Berçin [11] have derived the governing differential equations of motion and obtained solutions for various boundary conditions using Mathematica. Kollár [12] presented the analysis of the natural frequency of composite beams. Arpaci and Bozdag [13] have extended the approach to triply coupled vibrations of thin-walled beams. Arpaci et al. [14] presented an exact analytical method for predicting the undamped natural frequencies of beams with thinwalled open cross-sections having no axis of symmetry.

Prokic [15 ] analyzed triply coupled vibrations of thin-walled beams with arbitrary open cross-section. Starting from the Vlasov's theory, the governing differential equations for coupled bending and torsional vibrations were performed using the principle of virtual displacements. In the case of a simply supported thinwalled beam, a closed-form solution for the natural frequencies of free harmonic vibrations was derived.

Prokic' [16] analyzed the fivefold coupled vibrations of Timoshenko beams. A dynamic transfer matrix method has been presented by Li et al. [17] and the boundary element method was developed by Sapountzakis and Tsiatas [18]. Recently Orloske et al. [19] and Orloske and Parker [20], studied the stability and vibration characteristics of axially moving beams and Chen and Hsiao [21] investigated the coupled vibration induced by the boundary conditions. Hijmissen and Horssen [22] considered the change of frequencies of a standing cantilevered beam subjected to gravity load. Chen and Hsiao [23] investigated the coupled vibration of thin-walled beams with a generic open section induced by the boundary conditions by using the finite element method. Numerical examples were presented to demonstrate the accuracy of the proposed method and to investigate the effects of different pin ends on the coupled vibrations of the thin-wall beam. Vörös [24] has analyzed the free vibration and mode shapes of straight beams where the coupling between the bending and torsion was induced by steady state lateral loads.

Majority of the work cited above deal with mathematical solution techniques of beam vibration problems in which coupling interaction take places. There are limited numbers of numerical studies that investigate how the vibration characteristics are affected by the associated parameters. For this purpose, in the analyses in which the first ten natural vibration modes are considered, the effect of several parameters on natural vibration modes of the beam analyzed. The parameters considered include mass density, elasticity modulus, shear modulus, Poisson ratio.

The triply coupling vibration behaviors of material properties are investigated with the details that has never been that previously. As such this deterministic study is envisaged to fill an important gap in literature. 


\section{TRIPLY COUPLING EQUATIONS}

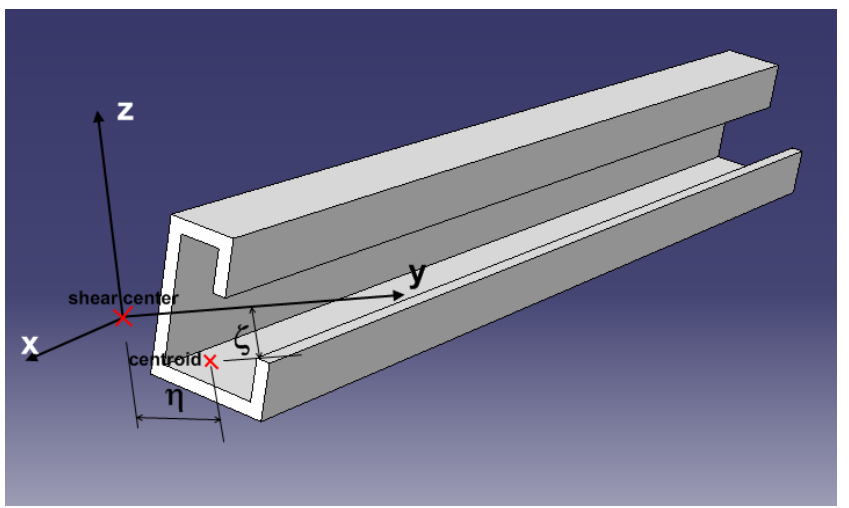

Figure 1 Beam without Symmetry Axis

A uniform straight thin-walled beam of length $L$ is shown in Fig. 1. The cross section of the beam is nonsymmetrical. In the right handed Cartesian coordinate system shown in Figure 1, the $\mathrm{x}$ axis is assumed to coincide with the elastic axis (i.e. loci of the shear center of the cross section of the thin-walled beam). The $y$ and $z$ axes are the principal axes of inertia passing through the shear center. The mass axis (i.e. loci of the centroid of the cross section of the thin-walled beam) is separated from $y$ and $z$ axes by the distance $\zeta$ and $\eta$ respectively. The bending translation in the $z$ direction, the bending translation in the $\mathrm{y}$ direction and the torsional rotation about the $\mathrm{x}$ axis of the shear center are denoted by $\mathrm{v}, \mathrm{w}$ and $\psi$ respectively, where $\mathrm{x}$ and $\mathrm{t}$ denote distance from the origin and time respectively. A constant compression axial force $\mathrm{P}$ is assumed to act through the centroid of the cross section of the thin-walled beam. The governing equations of motion of nonsymmetrical axially loaded thin-walled Euler-Bernoulli beam element including warping effect can be written as following three coupled differential equations, which can be derived by using d'Alembert's principle

$$
\begin{aligned}
& E I_{y} v^{I V}+P\left(v^{I I}-\eta \psi^{I I}\right)+\mu \ddot{v}-\mu \eta \ddot{\psi}=0 \\
& E I_{z} w^{I I}+P\left(w^{I I}-\zeta \psi^{I I}\right)+\mu \ddot{w}+\mu \zeta \ddot{\psi}=0 \\
& G J \psi^{I I}-P\left(I_{s} \psi^{I I} / \mu-\eta v^{I I}+\zeta w^{I I}\right)+\mu \eta \ddot{v}-\mu \zeta \ddot{w}-E \Gamma \psi^{I V}=0 \\
& v(x, t)=V(x) \sin \omega t \\
& w(x, t)=W(x) \sin \omega t \\
& \psi(x, t)=\Psi(x) \sin \omega t
\end{aligned}
$$

$\mathrm{V}, \mathrm{W}$ and $\Psi$ are the amplitudes of the sinusoidally varying bending translations and torsional rotation, respectively.

$$
\begin{aligned}
& E I_{y} V^{I V}+P\left(V^{I I}-\eta \Psi^{I I}\right)+\mu \ddot{V}-\mu \eta \ddot{\Psi}=0 \\
& E I_{z} W^{I V}+P\left(W^{I I}-\zeta \Psi^{I I}\right)+\mu \ddot{W}+\mu \check{\Psi}=0 \\
& G J \Psi^{I I}-P\left(I_{s} \Psi^{I I} / \mu-\eta V^{I I}+\zeta W^{I I}\right)+\mu \eta \ddot{V}-\mu \zeta \ddot{W}-E \Gamma \Psi^{I V}=0
\end{aligned}
$$


$\mathrm{E}$ is Young's modulus of elasticity and $\mathrm{G}$ is the shear modulus of the material, $\mathrm{EI}_{\mathrm{y}}$ and $\mathrm{EI}_{\mathrm{z}}$ are the bending stiffnesses of the thin-walled beam about the centriodal principal axes, which are parallel to the $\mathrm{y}$ and $\mathrm{z}$ axes, respectively. GJ and $\mathrm{E} \Gamma$ are torsional stiffness and warping stiffness of the thin-walled beam, respectively. $\mu$ is mass of the thin-walled beam per unit length, $I_{S}$ is polar mass moment of inertia per unit length beam cross section about $\mathrm{x}$ axis, superscript primes and dots denote the differentiation with respect to coordinate $\mathrm{x}$ and time $\mathrm{t}$ respectively. And notation $\omega$ shows circular frequency.

\section{NUMERICAL METHOD}

In the finite difference method (FDM), one can replace the differential operators $\mathrm{d}$ and $\partial$ by difference operator $\Delta$. To obtain finite difference expressions for derivatives, we approximate the function $y=f(x)$ a given interval by an interpolating polynomial $\Theta(\mathrm{x})$ and accept $\Theta^{\prime}(x), \Theta^{\prime \prime}(x), \Theta^{\prime \prime \prime}(x), \ldots$ in place of $f^{\prime}(x), f^{\prime \prime}(x), f^{\prime \prime \prime}(x), \ldots$ It is evident that a better polynomial approximation of the original function $f(x)$ at the so-called pivotal point $\mathrm{m}$ yields better finite difference expressions and therefore improves accuracy.

The simplest way of obtaining usable finite difference expressions for the first and second derivatives of a function $y=f(x)$ at a point $\mathrm{m}$ is by substituting for $f(x)$ a second-order parabola through a number of equally placed points, as shown in Fig. 1 This collocating polynomial using $\Delta \mathrm{x}$ intervals between points can be expressed by

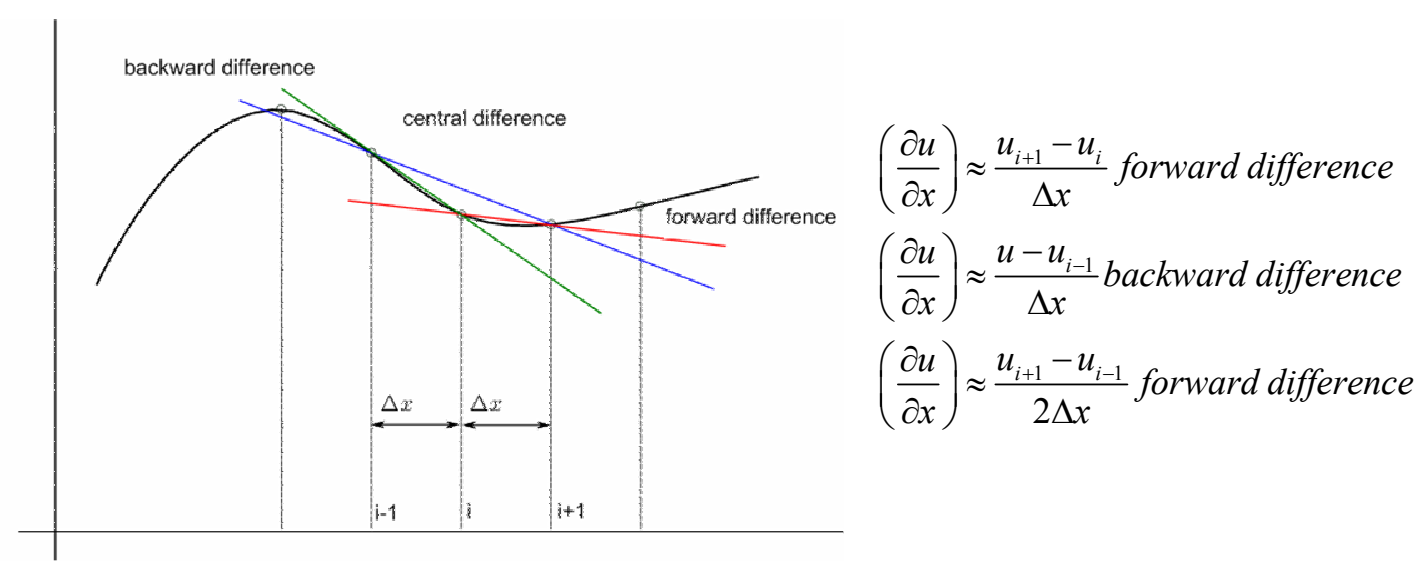

Figure 2 Basic Finite Difference Approximations

$$
\begin{aligned}
& \Theta^{\prime}=\frac{y_{m+1}-y_{m-1}}{2 \Delta x}+\frac{y_{m+1}-2 y_{m}+y_{m-1}}{\Delta x^{2}} \cdot x \\
& \Theta=y_{m}+\frac{y_{m+1}-y_{m-1}}{2 \Delta x} \cdot x+\frac{y_{m+1}-2 y_{m}+y_{m-1}}{\Delta x^{2}} \cdot \frac{x^{2}}{2}
\end{aligned}
$$


Since the pivotal point $\mathrm{m}$ is located at $\mathrm{x}_{\mathrm{m}}=0$, first derivative of the original function can be approximated by

$$
\left(\frac{d y}{d x}\right)_{m} \approx\left(\frac{\Delta y}{\Delta x}\right)_{m}=\left[\Theta^{\prime}(x)\right]_{m}=\frac{1}{2(\Delta x)}\left(y_{m+1}-y_{m-1}\right) .
$$

Similarly, the finite difference expression for the second derivative is

$$
\left(\frac{d^{2} y}{d x^{2}}\right)_{m}=\left[\frac{d}{d x}\left(\frac{d y}{d x}\right)\right]_{m} \approx\left(\frac{\Delta^{2} y}{\Delta x^{2}}\right)_{m}=\Theta^{\prime \prime}(x)_{m}=\frac{1}{(\Delta x)^{2}}\left(y_{m+1}-2 y_{m}+y_{m-1}\right) \text {. }
$$

A procedure identical to that used above yields the higher-order derivatives

$$
\begin{aligned}
\left(\frac{d^{3} y}{d x^{3}}\right)_{m} & \approx\left[\frac{\Delta}{2(\Delta x)}\left(\frac{\Delta^{2} y}{\Delta x^{2}}\right)\right]_{m}=\frac{1}{2(\Delta x)^{3}}\left(\Delta^{2} y_{m+1}-\Delta^{2} y_{m-1}\right) \\
& =\frac{1}{2(\Delta x)^{3}}\left(y_{m+2}-2 y_{m+1}+2 y_{m-1}-y_{m-2}\right)
\end{aligned}
$$

and

$$
\begin{aligned}
\left(\frac{d^{4} y}{d x^{4}}\right)_{m} & \approx\left(\frac{\Delta^{4} y}{\Delta y^{4}}\right)_{m}=\left[\frac{\Delta}{\Delta x}\left(\frac{\Delta^{3} y}{\Delta x^{3}}\right)\right]_{m}=\frac{1}{(\Delta x)^{4}}\left(\Delta^{3} y_{m+1 / 2}-\Delta^{3} y_{m+1 / 2}\right) \\
& =\frac{1}{(\Delta x)^{4}}\left(\Delta^{2} y_{m+1}-2 \Delta^{2} y_{m}+\Delta^{2} y_{m-1}\right) \\
& =\frac{1}{(\Delta x)^{4}}\left(y_{m+2}-4 y_{m+1}+6 y_{m}-4 y_{m-1}+y_{m-2}\right),
\end{aligned}
$$

The physical meaning of central differences is also shown in Figure 2. That is, using a second-order parabola for interpolating polynomials, the slope of the chord line from point $\mathrm{x}_{\mathrm{m}-1}$ to point $\mathrm{x}_{\mathrm{m}+1}$ becomes identical to that of the tangent at point $\mathrm{x}_{\mathrm{m}}$. We shall thereafter consider only central differences because of their higher accuracy.

$$
\begin{aligned}
& E I_{y}\left(V_{m-2}-4 V_{m-1}+6 V_{m}-4 V_{m+1}+V_{m+2}\right)+P \Delta^{2}\left(V_{m-1}-2 V_{m}+V_{m+1}\right) \\
& +P \eta \Delta^{2}\left(\varphi_{m-1}-2 \varphi_{m}+\varphi_{m+1}\right)-\Delta^{4} \mu \omega^{2} V_{m}+\Delta^{4} \mu \eta \omega^{2} \varphi_{m}=0 \\
& E I_{z}\left(W_{m-2}-4 W_{m-1}+6 W_{m}-4 W_{m+1}+W_{m+2}\right)+P \Delta^{2}\left(W_{m-1}-2 W_{m}+W_{m+1}\right) \\
& +P \Delta^{2} \zeta\left(\varphi_{m-1}-2 \varphi_{m}+\varphi_{m+1}\right)-\Delta^{4} \mu \omega^{2} W_{m}-\Delta^{4} \mu \omega^{2} \zeta \varphi_{m}=0 \\
& G J \Delta^{2}\left(\varphi_{m-1}-2 \varphi_{m}+\varphi_{m+1}\right)-\frac{P I_{S} \Delta^{2}}{\mu}\left(\varphi_{m-1}-2 \varphi_{m}+\varphi_{m+1}\right) \\
& +P \Delta^{2} \eta\left(V_{m-1}-2 V_{m}+V_{m+1}\right)-P \Delta^{2} \zeta\left(W_{m-1}-2 W_{m}+W_{m+1}\right) \\
& +I_{S} \omega^{2} \Delta^{4} \varphi_{m}-\mu \eta \omega^{2} \Delta^{4} V_{m}+\mu \zeta \omega^{2} \Delta^{4} W_{m} \\
& -E \Gamma\left(\varphi_{m-2}-4 \varphi_{m-1}+6 \varphi_{m}-4 \varphi_{m+1}+\varphi_{m+2}\right)=0
\end{aligned}
$$

Number of unknown rotations and displacements were approximately three times as the number of nodes on discritized beam. Three equations of system each having its own three different mesh layers, and supporting conditions must be applied considering the mesh of layers. 


\section{NUMERICAL RESULTS}

\subsection{Convergence Study}

The comparison of results for the first ten natural frequencies of the axially loaded beam with an axial force of $\mathrm{P}=1790 \mathrm{~N}$ is also made by including the effect of warping stiffness. The case of boundary conditions clamped on supports applied by taking the three variable functions and derivatives of the functions are zero when pivotal point on supports. For eliminating support issue and for comparing only material properties, all results obtained for the systems have same support conditions as clamped-clamped.

The particular thin-walled beam with a semi-circular cross section is considered. The geometrical and physical properties of the thin-walled beam and axial load are given below:

$$
\begin{array}{lll}
I_{y}=9.26 \square 0^{-8} \mathrm{~m}^{4} & I_{z}=1.77 \square 0^{-8} \mathrm{~m}^{4} & J=1.64 \square 0^{-8} \mathrm{~m}^{4} \\
I_{S}=0.000501 \mathrm{kgm} & \Gamma=1.52 \square 0^{-12} \mathrm{~m}^{6} & L=0.82 \mathrm{~m} \\
y_{C}=0.0155 \mathrm{~m} & z_{C}=0 \mathrm{~m} & \mu=0.835 \mathrm{kgm}^{-1} \\
E=68.9 \square 0^{9} \mathrm{Nm}^{-2} & G=26.5 \square 0^{9} \mathrm{Nm}^{-2} & P=1790 \mathrm{~N}
\end{array}
$$

\begin{tabular}{|c|c|c|c|c|c|c|c|c|c|c|}
\hline $\begin{array}{c}\text { Number } \\
\text { of } \\
\text { Nodes }\end{array}$ & Mod1 & Mod2 & Mod3 & Mod4 & Mod5 & Mod6 & Mod7 & Mod8 & Mod9 & Mod10 \\
\hline 8 & 184.50 & 184.61 & 378.52 & 467.91 & 552.11 & 597.14 & 749.09 & 821.51 & 894.55 & 989.28 \\
\hline 9 & 186.48 & 187.87 & 385.77 & 485.71 & 566.28 & 612.61 & 791.82 & 873.45 & 973.66 & 1117.86 \\
\hline 10 & 187.96 & 190.25 & 391.30 & 498.69 & 576.28 & 624.61 & 824.27 & 912.27 & 1034.55 & 1218.94 \\
\hline 11 & 189.15 & 192.00 & 395.65 & 508.40 & 583.59 & 634.12 & 849.54 & 941.87 & 1082.36 & 1299.46 \\
\hline 12 & 190.13 & 193.32 & 399.12 & 515.83 & 589.09 & 641.77 & 869.61 & 964.86 & 1120.56 & 1364.43 \\
\hline 13 & 190.93 & 194.34 & 401.95 & 521.63 & 593.34 & 648.02 & 885.82 & 983.02 & 1151.54 & 1417.47 \\
\hline 15 & 192.16 & 195.78 & 406.20 & 529.96 & 599.36 & 657.40 & 910.08 & 1009.43 & 1198.12 & 1497.69 \\
\hline 17 & 193.04 & 196.73 & 409.21 & 535.51 & 603.34 & 664.17 & 927.07 & 1027.27 & 1230.86 & 1554.13 \\
\hline 20 & 193.95 & 197.64 & 412.27 & 540.90 & 607.17 & 671.03 & 944.32 & 1044.79 & 1264.21 & 1610.47 \\
\hline 25 & 194.85 & 198.48 & 415.28 & 545.90 & 610.71 & 677.78 & 961.14 & 1061.23 & 1296.84 & 1654.22 \\
\hline 30 & 195.35 & 198.93 & 416.96 & 548.59 & 612.60 & 681.58 & 970.55 & 1070.13 & 1315.15 & 1666.93 \\
\hline 40 & 195.87 & 199.36 & 418.67 & 551.23 & 614.46 & 685.44 & 980.07 & 1078.93 & 1333.73 & 1676.50 \\
\hline 50 & 196.12 & 199.56 & 419.47 & 552.43 & 615.30 & 687.25 & 984.53 & 1082.96 & 1342.44 & 1680.54 \\
\hline 80 & 196.38 & 199.77 & 420.33 & 553.72 & 616.20 & 689.22 & 989.37 & 1087.28 & 1351.91 & 1684.75 \\
\hline 100 & 196.44 & 199.82 & 420.53 & 554.01 & 616.41 & 689.67 & 990.48 & 1088.27 & 1354.09 & 1685.69 \\
\hline 200 & 196.52 & 199.89 & 420.80 & 554.40 & 616.68 & 690.27 & 991.96 & 1089.57 & 1356.99 & 1686.94 \\
\hline 250 & 196.53 & 199.89 & 420.83 & 554.45 & 616.71 & 690.34 & 992.13 & 1089.73 & 1357.34 & 1687.09 \\
\hline 500 & 196.55 & 199.90 & 420.87 & 554.51 & 616.75 & 690.44 & 992.37 & 1089.93 & 1357.80 & 1687.28 \\
\hline 600 & 196.55 & 199.91 & 420.88 & 554.52 & 616.76 & 690.45 & 992.38 & 1089.95 & 1357.84 & 1687.30 \\
\hline 750 & 196.55 & 199.91 & 420.88 & 554.52 & 616.76 & 690.46 & 992.41 & 1089.97 & 1357.88 & 1687.32 \\
\hline 900 & 196.55 & 199.91 & 420.88 & 554.52 & 616.76 & 690.46 & 992.42 & 1089.98 & 1357.90 & 1687.33 \\
\hline 1000 & 196.55 & 199.91 & 420.88 & 554.52 & 616.77 & 690.46 & 992.43 & 1089.98 & 1357.91 & 1687.33 \\
\hline Ref [17] & 196.55 & 199.91 & 420.89 & 554.53 & 616.77 & 690.47 & 992.45 & 1090.00 & 1357.95 & 1687.35 \\
\hline
\end{tabular}

Table 1. Convergence Results for the First Ten Modes.

The numerical results are shown in Table 1 compared with those available in the literature [17]. It is shown that the convergence with respect to mesh size is precisely good and the frequency parameter closes its analytical value from below monotonically. Differences between the results and Ref. [17] are less then \%0.1. Generally, convergency ratio shows faster approximation for lower modes than high ones. In this paper, all calculations were done for the beams having 1000 numbered mesh size. 


\subsection{Verification}

The first ten bending-torsion coupled natural frequencies of the unloaded beam (i.e. $\mathrm{P}=0$ ) are calculated for clamped end conditions by excluding and including the effect of warping stiffness. Further comparison of results for the first ten natural frequencies of the axially loaded beam with an axial force of $\mathrm{P}=1790 \mathrm{~N}$ is also made by excluding and including the effect of warping stiffness. The numerical results are also shown in Tables 2 and compared with Li et al. [17]. It can be seen from Table 2, for the unloaded beam, the present results and the published results are completely the same. For the axially loaded beam with an axial force of $\mathrm{P}=1790 \mathrm{~N}$, the maximum relative error between the present results and the published results is less than $0.1 \%$.

Table 2. Natural frequencies of thin-walled beam with Clamped-Clamped end condition

\begin{tabular}{|c|c|c|c|c|c|c|c|c|}
\hline \multirow{4}{*}{$\begin{array}{c}\text { Mode } \\
\text { Number }\end{array}$} & \multicolumn{8}{|c|}{ Natural Frequency (Hz) } \\
\hline & \multicolumn{4}{|c|}{ Warping Ignored } & \multicolumn{4}{|c|}{ Warping Included } \\
\hline & $\begin{array}{l}\text { Li et al } \\
{[17]}\end{array}$ & $\begin{array}{l}\text { Present } \\
\text { Study }\end{array}$ & $\begin{array}{l}\text { Li et al } \\
{[17]}\end{array}$ & $\begin{array}{l}\text { Present } \\
\text { Study }\end{array}$ & $\begin{array}{l}\text { Li et al } \\
{[17]}\end{array}$ & $\begin{array}{l}\text { Present } \\
\text { Study }\end{array}$ & $\begin{array}{l}\text { Li et al } \\
{[17]}\end{array}$ & $\begin{array}{l}\text { Present } \\
\text { Study }\end{array}$ \\
\hline & $\mathrm{P}=0$ & $\mathrm{P}=0$ & $\mathrm{P}=1790$ & $\mathrm{P}=1790$ & $\mathrm{P}=0$ & $\mathrm{P}=0$ & $\mathrm{P}=1790$ & $\mathrm{P}=1790$ \\
\hline 1 & 174.08 & 174.0873 & 171.77 & 171.7774 & 198.81 & 198.8108 & 196.55 & 196.5541 \\
\hline 2 & 202.38 & 202.3829 & 199.91 & 199.9117 & 202.38 & 202.3829 & 199.91 & 199.9119 \\
\hline 3 & 353.58 & 353.589 & 349.05 & 349.0493 & 425.04 & 425.0422 & 420.89 & 420.8875 \\
\hline 4 & 522.20 & 522.1996 & 515.85 & 515.8534 & 557.87 & 557.8731 & 554.53 & 554.5292 \\
\hline 5 & 557.87 & 557.8729 & 554.53 & 554.5293 & 618.09 & 618.0901 & 616.77 & 616.7704 \\
\hline 6 & 630.19 & 630.1913 & 628.89 & 628.8876 & 695.63 & 695.6299 & 690.47 & 690.4675 \\
\hline 7 & 712.12 & 712.1193 & 703.12 & 703.1165 & 999.31 & 999.3004 & 992.45 & 992.4325 \\
\hline 8 & 893.88 & 893.8721 & 882.69 & 882.6898 & 1093.66 & 1093.647 & 1090.00 & 1089.989 \\
\hline 9 & 1072.90 & 1072.886 & 1059.45 & 1059.441 & 1365.73 & 1365.692 & 1357.95 & 1357.916 \\
\hline 10 & 1093.66 & 1093.647 & 1090.00 & 1089.989 & 1688.57 & 1688.555 & 1687.35 & 1687.335 \\
\hline
\end{tabular}

\subsection{Analysis}
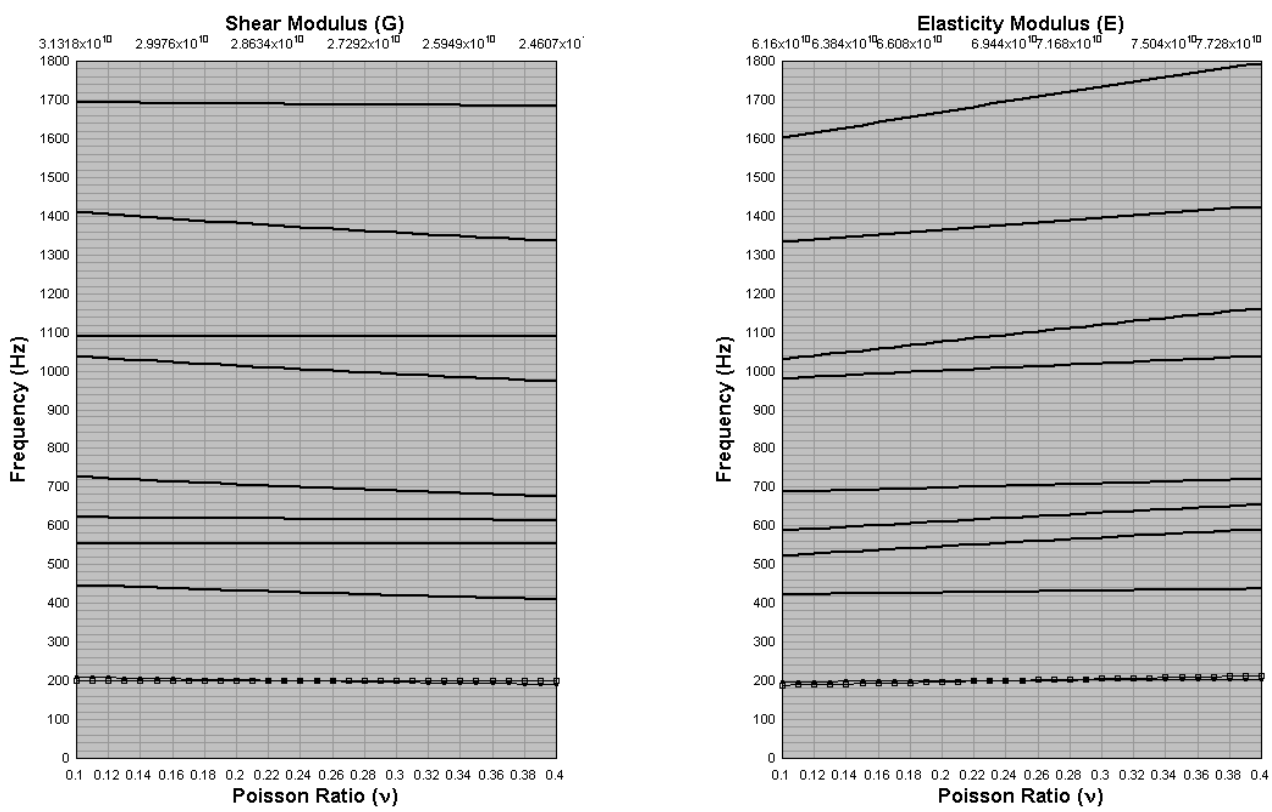

Figure 3 Effect of Poisson's Ratio a) For fixed Elasticity modulus $\left(68.9 \mathrm{e} 9 \mathrm{~N} / \mathrm{m}^{2}\right)$

b) For fixed Shear modulus $\left(2.8 \mathrm{e} 10 \mathrm{~N} / \mathrm{m}^{2}\right)$ 
One can see the effect of Poisson's ratio on the first ten natural frequencies in Figure 3. Curves in Figure 3(a) and Figure 3(b) were plotted for fixed values of modulus of elasticity $E=68.9 \mathrm{e} 9 \mathrm{~N} / \mathrm{m}^{2}$ and shear modulus $\mathrm{G}=2.8 \mathrm{e} 10 \mathrm{~N} / \mathrm{m}^{2}$ respectively. It is obviously seen that the Poisson's ratio can change the frequencies of modes and additionally it can change the order of the modes as fundamental mode.

It is well known that the effect of material modulus on natural frequencies of symmetric beams in classical vibration problems which analyze only transversal modes or only longitudinal modes or etc. The effect of Poisson's ratio on natural frequencies is monotonic for all modes in classical vibration problems. But, in the beams without symmetry axis, the effect of ratio of modulus is more important than the modulus, since different modulus have different degrees of effects on different vibration types. As a result, the Poisson's ratio which demonstrates a kind of ratio between elasticity modulus and shear modulus has critical importance for coupled vibration problems.

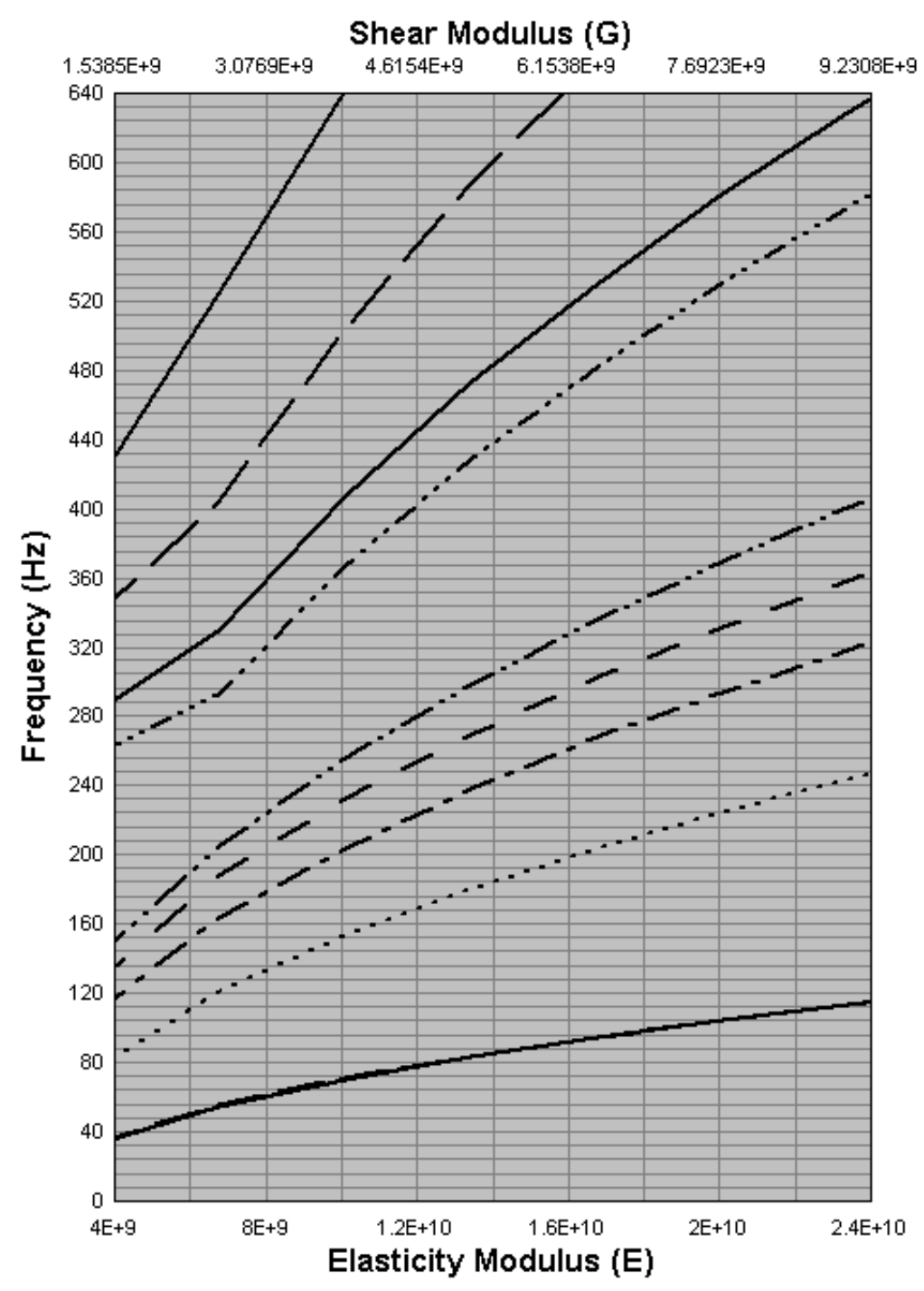

Figure 4. Effect of Elasticity Modulus for Fixed Poisson's Ratio (0.3) 
Figure 4 shows the effect of modulus of elasticity on natural frequencies for fixed value of Poisson's ratio $(v=0.3)$. When the value of elasticity modulus increased, so did natural frequencies. It is important to point in this graphic that there was bigger variation range of elasticity modulus used in Figure 4 than Figure 3, but there was no apparent change for mode sequence in the range of consideration.

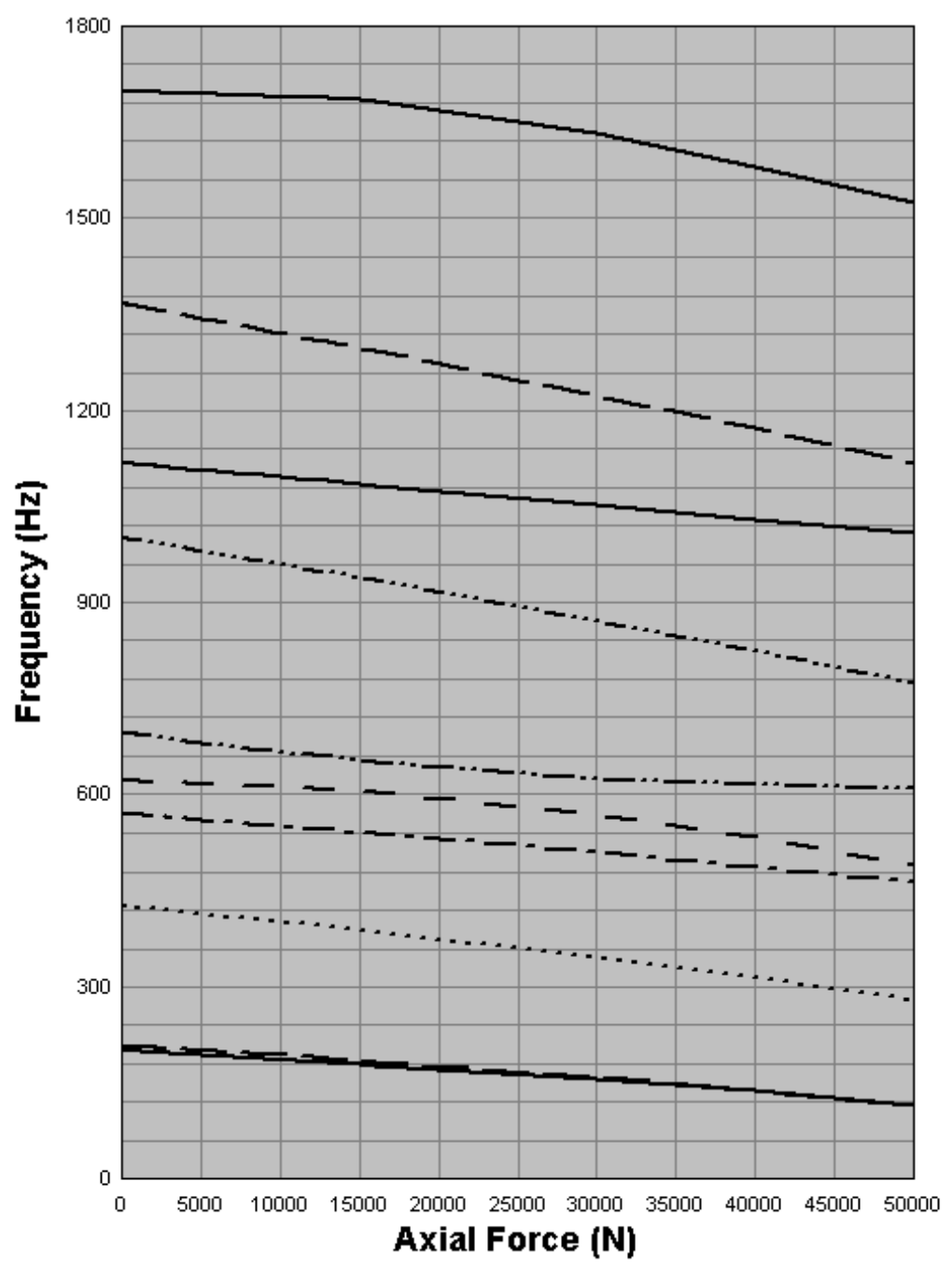

Figure 5. Effect of Axial Force on Natural Frequencies

Figure 5 shows the effect of axial force on the first ten modes. All modes decreased by increasing axial force monotonically. 


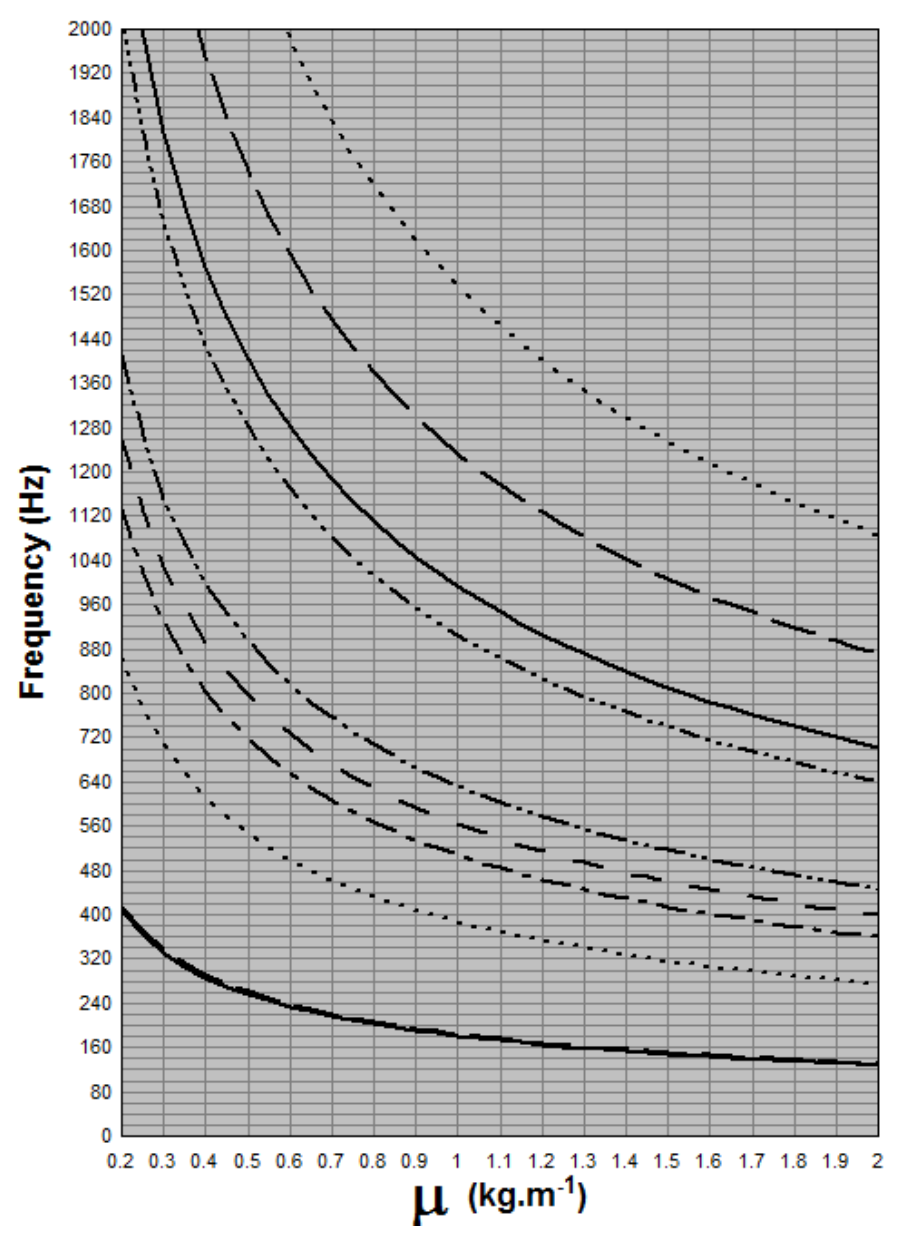

Figure 6. Effect of Mass Density on Natural Frequencies $(\mathrm{P}=0)$

Easily, one can see the important effects of mass density on natural frequency in Figure 6. It can be seen from Figure 6 that natural frequency values of modes are inversely proportional with the variation of the mass density. For smaller values of mass density, the natural frequencies had high sensitivity.

\section{CONCLUSION}

The present study was designed to determine the effect of material properties on natural vibrations of beams without symmetry axis. A model based on finite difference technique was improved and verification analysis showed that the method could be used to simulate the system precisely.

Effect of shear and elasticity modulus, mass density, Poisson's ratio was individually investigated in certain ranges. The natural frequency values of modes are inversely proportional with the variation of the mass density for all mode types. Frequencies had high sensitivity to variation of the mass density for smaller values. Poisson ratio is a more important parameter than material modulus for beams without symmetry axis. At constant Poisson's ratio, the effect of material modulus is expectable on beams with or without symmetry axis. There are monotonic effects on variations of 
natural frequencies. But, the variation of Poisson's ratio can change the variation ratio of different type of modes. This event can be interpreted by the explanation of that every modulus has different effect level on different mode types in coupling problems. Effect of axial load was also investigated in this study. The effects of axial load on natural frequency were found to be monotonic. There was reverse relationship between the value of axial load and natural frequencies. In the range of investigation, axial load caused considerable changes on natural frequencies. In this respect axial load could be a tuning parameter for natural frequencies in practical applications.

Although these findings enhance our understanding of effect of material properties on natural frequencies of coupled beams without symmetry axis, this research has thrown up many questions in need of further investigation.

For practical usage of beams without symmetry axis, parametric analysis is a necessity instead of single point analysis and all calculations and analysis must be done as precisely as one could.

\section{REFERENCES}

1. J. M. Gere and Y. K. Lin, Coupled Vibrations Of Thin-Walled Beams Of Open CrossSection. Journal of Applied Mechanics, Transactions of the American Society of Mechanical Engineers, 80, 373-378, 1958.

2. Y. K. Lin, Coupled Vibrations Of Restrained Thin-Walled Beams. Journal of Applied Mechanics, Transactions of the American Society of Mechanical Engineers, 82, 739-740, 1960.

3. R. E. D. Bishop, W. G. Price and Z. Xi-Cheng, A Note On The Dynamical Behaviour of Uniform Beams Having Open Channel Section. Journal of Sound and Vibration, 99, 155-167, 1985.

4. P. O. Freiberg, Beam Element Matrices Derived From Vlasov's Theory of Open Thin-Walled Elastic Beams. International Journal for Numerical Methods in Engineering, 21, 1205-1228, 1985.

5. E. Dokumaci, An Exact Solution For Coupled Bending And Torsion Vibrations of Uniform Beams Having Single Cross-Sectional Symmetry. Journal of Sound and Vibration, 119, 443-449, 1987.

6. R.E.D. Bishop, S.M., Cannon, and S., Miao, On Coupled Bending And Torsional Vibration Of Uniform Beams. Journal of Sound and Vibration, 131, 457-464, 1989.

7. D. J. Mead and Y. Yaman, The Harmonic Response Of Uniform Beams On Multiple Linear Supports: A Flexural Wave Analysis. Journal of Sound And Vibration, 141, 465-484, 1990.

8. J.R., Banerjee, F.W., Williams, Coupled Bending-Torsional Dynamic Stiffness Matrix of An Axially Loaded Timoshenko Beam Element. International Journal of Solids and Structures, 31, 749-762, 1994.

9. Y.Yaman, Vibration of Open-Section Channels: A Coupled Flexural And Torsional Wave Analysis. Journal of Sound and Vibration, 204(1):131-58, 1997.

10. Y. Yaman, Analytical Modelling of Coupled Vibrations of Elastically Supported Channels. Proceedings of the 6th International Conference on Recent Advances in Structural Dynamics, university of Southampton, England, 1997. 
11. M. Tanaka, A.N. Bercin, Free Vibration Solution For Uniform Beams of Nonsymmetrical Cross Section Using Mathematica. Computers and Structures, 71:18,1999 .

12. P.L. Kollár, Flexural-Torsional Vibration Of Open Section Composite Beams With Shear Deformation. International Journal of Solids and Structures, 38, 75437558,2001.

13. A. Arpaci, E. Bozdag, On The Free Vibration Analysis of Thin-Walled Beams With Nonsymmetric Open Cross Sections. Computers and Structures, 80, 691695,2002 .

14. A. Arpaci, S.E. Bozdag and E. Sunbuloglu, Triply coupled vibrations of thin-walled open cross-section beams including rotary inertia effects. Journal of Sound and Vibration, 260, 889-900, 2003.

15. A. Prokic, On triply coupled vibrations of thin-walled beams with arbitrary crosssection. Journal of Sound and Vibration, 279, 723-737, 2005.

16. A. Prokic, On Fivefold Coupled Vibrations of Timoshenko Thin-Walled Beams. Engineering Structures, 28, 54-62,2006.

17. J. Li, W. Li, R. Shen, and H. Hua, Coupled Bending and Torsional Vibration of Nonsymmetrical Axially Loaded Thin-Walled Bernoulli-Euler Beams. Mechanics Research Communications, 31, 697-711,2004.

18. E.J. Sapountzakis, G.C. Tsiatas, Flexural-Torsional Vibrations of Beams by BEM. Computational Mechanics, 39, 409-417,2007.

19. Orloske, K., Leamy, M.J., Parker, R.G., Flexural-torsional buckling of misaligned axially moving beams, part I: three-dimensional modeling, equilibria, and bifurcations. International Journal of Solids and Structures, 43, 4297-4322, 2006.

20. K. Orloske, R.G. Parker, Flexural-Torsional Buckling of Misaligned Axially Moving Beams, Part II: Vibration and Stability Analysis. International Journal of Solids and Structures, 43, 4323-4341,2006.

21. H. H. Chen, K.M. Hsiao, Coupled Axial-Torsional Vibration of Thin Walled ZSection Beam Induced by Boundary Conditions. Thin-Walled Structures, 45, 573$583,2007$.

22. J.W. Hijmissen, W.T. Horssen, On Transverse Vibration of a Vertical Timoshenko Beam. Journal of Sound and Vibration, 314, 161-179,2008.

23. H. H. Chen, K. M. Hsiao, Quadruply Coupled Linear Free Vibrations of ThinWalled Beams With a Generic Open Section . Engineering Structures, 30, 13191334, 2008.

24. G. M. Vörös, On Coupled Bending-Torsional Vibrations of Beams with Initial Loads. Mechanics Research Communications, 36, 603-611, 2009. 